\title{
Experimental research on mechanical properties of high voltage transmission lines after the simulated wildfires
}

\author{
Tianzheng Wang ${ }^{1}$, Zhen Tang ${ }^{1}$, Xinwei Wang ${ }^{1}$, \\ Weiyi Chen ${ }^{2, a}$,Xiaogang $\mathrm{Wu}^{2}$, KechaoZhao ${ }^{2}$,Jinzhao Yang $^{2}$, Chong Zuo ${ }^{2}$ \\ ${ }^{1}$ State Grid Shanxi Electric Power Research Institute, Taiyuan 030001, China \\ ${ }^{2}$ College of Mechanics, Taiyuan University of Technology, Taiyuan 030024, China \\ ${ }^{a}$ College of Mechanics, Taiyuan University of Technology, Taiyuan 030024, China,chenweiyi211@163.com
}

\begin{abstract}
In order to determine whether the mechanical performance after the fires of high voltage transmission lines meets the requirements of normal use, this article simulates the wildfire, and does the mechanical performance experiment of high voltage transmission lines(HVT lines) after the simulated wildfires. The experiment studied the breaking force and elongation of each layer of 500kv HVT lines after the simulated wildfire. Experimental results show that, after fires, each layer of single aluminum wires of 500kv HVT lines have low breaking force which can be decreased obviously to half of that of new lines. For the steel core, decrease of breaking force is not obvious than aluminum wires, and with the increasing degree of wildfires, it increases gradually to a maximum of $35 \%$ of new steel lines' breaking force. After wildfires, aluminum lines' resistance ability of deformation decreases significantly, and its plastic deformation increases obviously during uniaxial tension. The steel core has little plastic deformation, and layers of aluminum become fluffy after fires. Therefore, the steel core main bearing load after wildfires.
\end{abstract}

\section{Introduction}

High voltage transmission lines is the lifeline of the national power grid and closely related to the National People's livelihood, but at the same time, high voltage transmission line is so fragile that any damage can cause large area blackout and even collapse [1]. In recent years, extreme weather caused a lot of fire accidents which not only is a threat to the safety of forest, personnel and property in the fire area, but also affects the safety and reliability of HVT lines through the forest. Wildfires are a serious threat to the safety of the HVT lines and the power grid. Except leading to tripping accidents, wildfire also can cause serious impact on HVT lines. After wildfires, because of the influence of high temperature, the tensile strength and the Conductive properties of HVT lines may be partly affected. Especially the strength, if the strength decreases obviously, it will constitute a major hidden danger of transmission security.

At present, there are numerous studies at home and abroad about tripping accident mechanism, breakdown characteristic, tripping cause analysis and countermeasures of the HVT lines suffered from wildfires, but there are less research reports of HVT lines about the changes of mechanical properties and the problems of safe load carrying ability after wildfires. Therefore, this paper studies on the mechanical properties of HTV lines after wildfires, and provides changes in the mechanical properties of HTV lines, in order to provide certain reference and guidance for the replacement work of HVT lines after wildfire accidents. In the experimental study, we refers to many research reports on thermal stability of HVT 
lines, controlling galloping of overhead power transmission line and temperature of HVT lines, and some studies on stress analysis of steel cored aluminum stranded wire. These articles provide important references for the study of our works [2-7].

\section{Experimental Method}

\subsection{Experimental Scheme}

First, understanding the mechanical properties of new transmission lines (JL/G1A-400/35) and the transmission lines (JL/G1A-400/35) and the transmission lines burned by wildfires through experiments, and serving the results as control group. Secondly, establishing a simulation environment of wildfires in the laboratory which is similar with the actual situation, and ensuring the feasibility of simulated wildfires through the comparison of mechanical properties with transmission lines burned by wildfires. Finally, comparing the mechanical properties of fired transmission lines with new transmission lines, and ensuring the mechanical properties of HVT lines after wildfires.

The HVT line of JL/G1A-400/35 is composed of four layers. The inner most layer steel core mainly absorb load, the outer three layers of aluminum mainly conduct. The number of steel core is 7 , and the number of aluminum lines is 48 .

Wildfire simulation can adopt two methods: burning the HVT lines by blowtorch or firewood. Then, ensuring which method is more accordant with actual through the comparison of mechanical properties with transmission lines burned by wildfires.

Experimental Equipment. As shown in Figure 1, tensile test of materials are tested in $10 \mathrm{t}$ universal testing machine. The experiment uses a constant displacement loading mode, and applying test specimen to fracture with speed of $15 \mathrm{~mm} / \mathrm{min}$. The experiment adopts flat chuck for fixing. The experimental results are collected by computer automatically. The experimental temperature is $20^{\circ} \mathrm{C}$. The blowtorch and firewood used for simulating wildfires are shown in Figure 2.

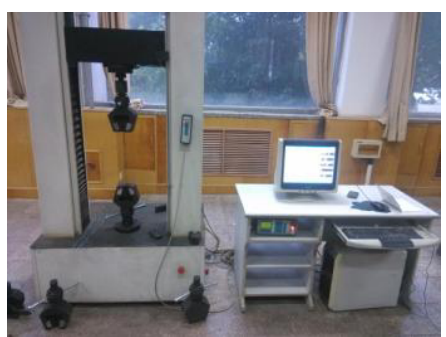

Figure 1. 10t Universal testing machine
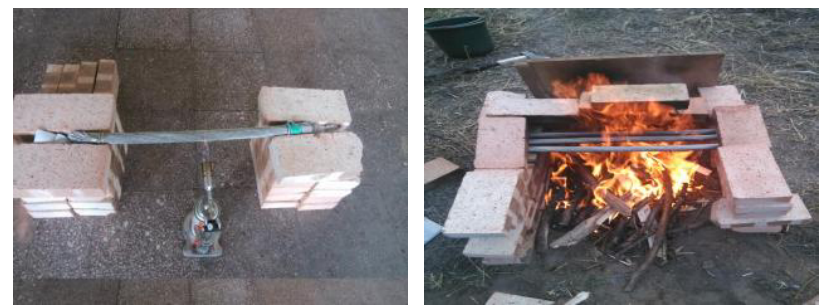

Figure 2. The picture of blowtorch and firewood

\section{Experimental Results}

\subsection{Experimental results of new HVT lines}

In the course of the experiment, we found that tensile curves of all aluminum lines have no obvious yield stage and reinforcement service stage, and the plastic deformation is very small. The tensile curves of steel core have obvious yield stage and reinforcement service stage. Figure 3 show the tensile curves.

Experimental results are shown in Table 1. It is consistent with the said of that tension stress increases gradually from the outer layer to the inner layer in document [7].
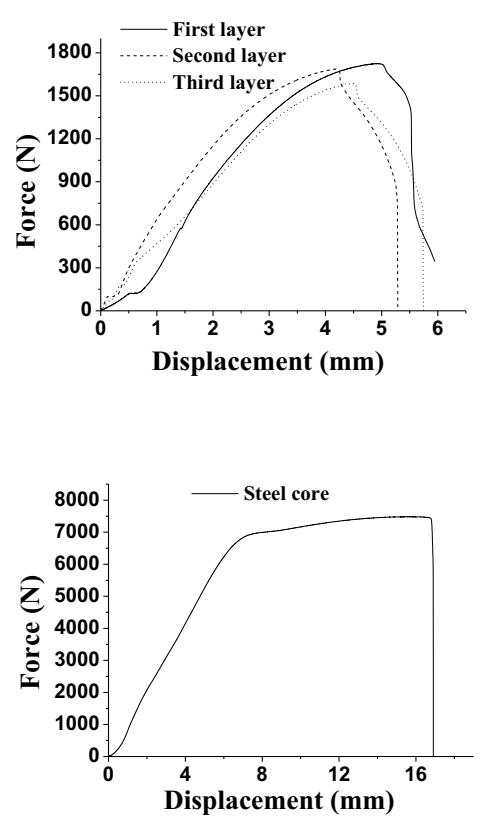

Figure 3. Tensile curves of new signal lines of every layer 
Table 1. Tensile Force and Elongation of New Transmission

\begin{tabular}{|c|c|c|c|c|}
\hline New wires & $\begin{array}{c}\text { First } \\
\text { layer }\end{array}$ & $\begin{array}{c}\text { Second } \\
\text { layer }\end{array}$ & $\begin{array}{c}\text { Third } \\
\text { layer }\end{array}$ & $\begin{array}{c}\text { Steel } \\
\text { core }\end{array}$ \\
\hline $\begin{array}{c}\text { Average tensile } \\
\text { force (N) }\end{array}$ & 1718 & 1677 & 1554 & 7483 \\
\hline $\begin{array}{c}\text { Average } \\
\text { elongation (\%) }\end{array}$ & 2.16 & 2.10 & 2.13 & - \\
\hline
\end{tabular}

Experimental results of the HVT lines burned by wildfires. As shown in Figure 4, the HVT lines retrieved from the scene of wildfires had been completely blackened in the outer layer, and the inner layers had been partly blackened. The tensile curve of the outermost aluminum layer has a long reinforcement service stage, but similar to new lines, the tensile curve of the second and third layers of aluminum lines has no obvious yield stage and reinforcement service stage. The tensile curves of steel core have obvious yield stage and reinforcement service stage. Figure 5 show the tensile curves.

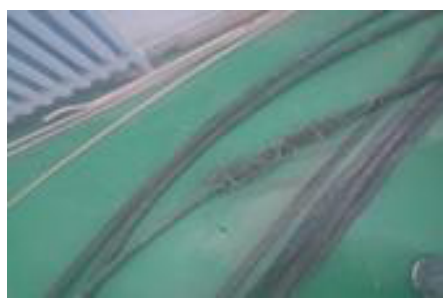

Figure 4. the HVT lines retrieved from the scene of wildfires

Experimental results are shown in Table 2. The average tensile force of the outermost aluminum layer is smallest, and the elongation of it is high. The average tensile force of the second and third layers of aluminum lines is closer, and it is much higher than the outermost aluminum layer, and the elongation of them is low. The average tensile force of the steel core is much higher than the aluminum lines.

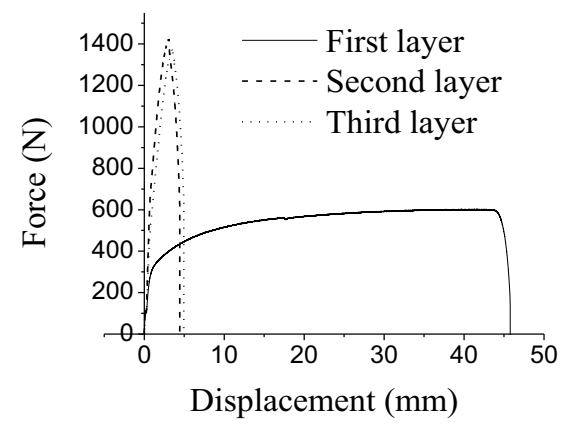

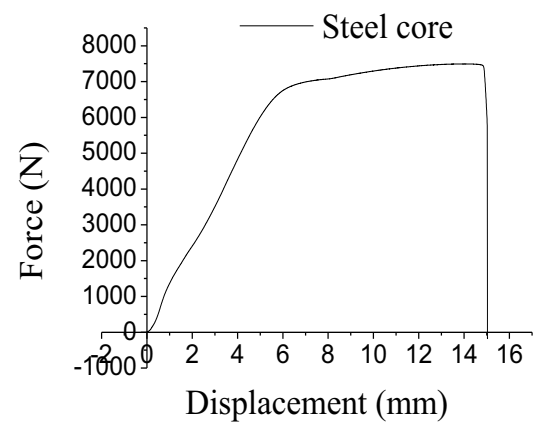

Figure 5. Tensile curves of signal lines burned by wildfires of every layer

Table 2. Tensile Force and Elongation of Transmission Lines

\begin{tabular}{|c|c|c|c|c|}
\multicolumn{7}{c}{ burned by wildfires } \\
\hline Wires of wildfires & $\begin{array}{c}\text { First } \\
\text { layer }\end{array}$ & $\begin{array}{c}\text { Second } \\
\text { layer }\end{array}$ & $\begin{array}{c}\text { Third } \\
\text { layer }\end{array}$ & $\begin{array}{c}\text { Steel } \\
\text { core }\end{array}$ \\
\hline $\begin{array}{c}\text { Average tensile } \\
\text { force (N) }\end{array}$ & 606 & 1410 & 1330 & 7494 \\
\hline $\begin{array}{c}\text { Average } \\
\text { elongation (\%) }\end{array}$ & 21.97 & 2.72 & 2.47 & - \\
\hline
\end{tabular}

\subsection{Experimental results of the HVT lines burned by blowtorch}

Experiment tested the tensile force of the front and the back of the HVT lines burned by blowtorch, and found: The tensile force of the front of the outermost layer of single aluminum lines decreases significantly; The tensile force of the back of the outermost layer of single aluminum lines decreases less. Experimental results are shown in Figure 6.

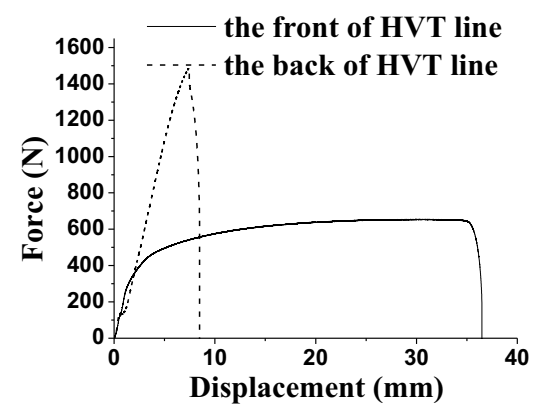

Fig.6 The tensile force of the outermost layer of aluminum lines burned by blowtorch

Experimental results of the HVT lines burned by firewood. Experiment was carried out with different burning degree of firewood on three HVT lines, in the course of the experiment we found: In the early burning stage of firewood, this three HVT lines are gradually blackened from the inside to the outside, In the later burning stage of firewood, the blackened layer of two 
internal HVT lines disappears, and the blackened degree of the outermost HVT lines increases. And all of the outermost layer of three HVT lines appear loose strands. Experimental results are shown in Figure 7.(The outermost root is the first, the middle root is the second, the innermost root is the third. ) Experimental results are shown in Table 3.
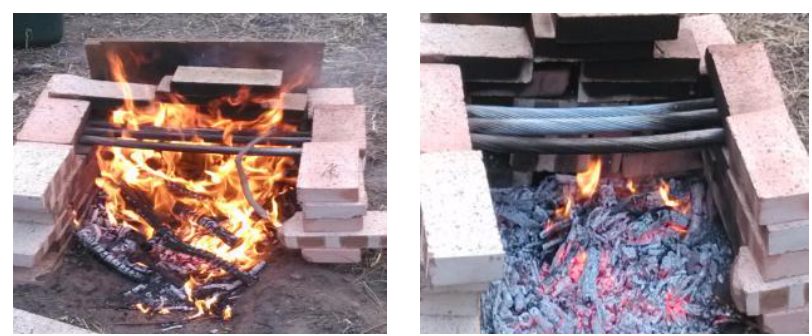

Figure 7. Process of HVT lines burned by firewood

Table 3. Tensile Force and Elongation of Transmission Lines burned by firewood

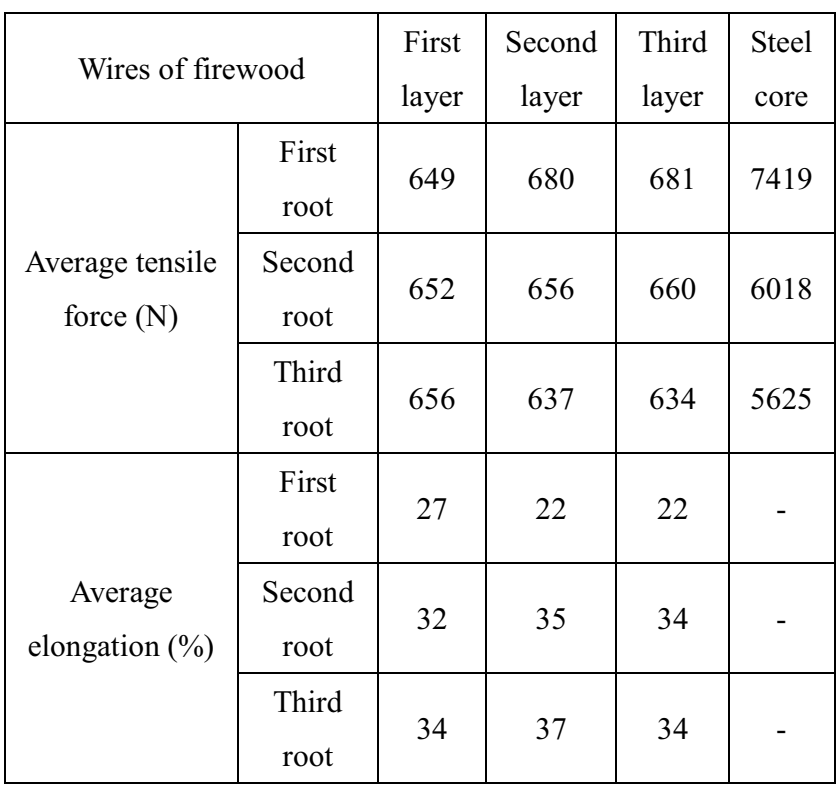

\section{The Analysis and Discussion of Results}

\subsection{Comparison and selection on two types of simulated wildfires}

It can be found from the results of $2.3,2.4$ that, the HVT lines burned by blowtorch have locality and inhomogeneity. But the HVT lines burned by firewood are under the condition of uniform heating, and it can reflect the real damage situation of HVT lines burned by wildfires better. So, the results of firewood should be selected.

\subsection{The judgment of the burning intensity of three HVT lines burned by firewood}

The ultimate strength of steel, experienced high temperature of $400^{\circ} \mathrm{C}$, varies little after cooling, compared with the ultimate strength of steel at normal temperature. The ultimate strength of steel, experienced high temperature of $400-700^{\circ} \mathrm{C}$, decreases after cooling, compared with the ultimate strength of steel at normal temperature. With the increase of temperature, the ultimate strength of steel decline rapidly[5]. The tensile force of steel cores decreases from the first HVT lines to the second HVT lines(see Table 3), and it shows that the temperature of steel cores increases from the first HVT lines to the second HVT lines. So, the burning degree of three HVT lines increases from the first to the third. For each HVT line.

\subsection{The change of the mechanical properties of HVT under different burning circumstances}

4.3.1 The change of the mechanical properties of aluminum lines of the second and third layers

According to the experimental results, burning can affect the tensile strength of aluminum lines. From the above table(Table1,2,3 )we can find: The tensile force of the second layer of HVT lines burned by wildfires decreases by $15.9 \%$, and the elongation of it increases by $25.9 \%$; The tensile force of the second layer of HVT lines burned by firewood decreases by $59.5 \%, 60.9 \%, 62.0 \%$, and the elongation of it increases to $22 \%, 35 \%, 37 \%$ from $2.1 \%$. The mechanical properties of the third layer of HVT lines are similar to the second layer.

The tensile curve of the second and third layers of aluminum lines under different burning circumstances, are shown in Figure 8. The shapes of tensile curve of the second and third layers of aluminum lines burned by wildfires are similar, and the tensile force has little difference. The shapes of tensile curve of the second and third layers of aluminum lines burned by firewood are obviously different from the shapes of tensile curve of the second and third layers of aluminum lines burned by wildfires. It shows that the different burning degrees have a great influence on the second and third layers of aluminum lines, and the simulation results can not reflect the real wildfire results. But estimation of the overall tensile force,based on the tensile force of aluminum lines burned by firewood, is on the safe side. 

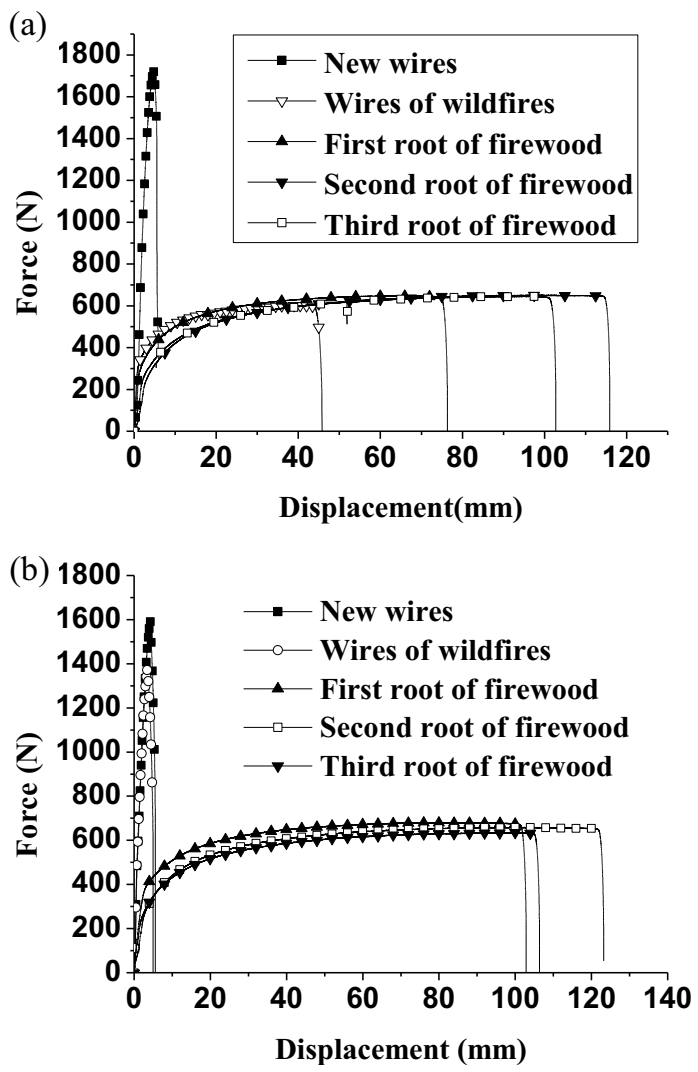

Figure 8. The tensile curve of the second(a) and third(b) layer of aluminum lines under different burning circumstances

\subsubsection{The change of the mechanical properties of the outermost layer of aluminum lines}

From the above table(Table1,2,3 )we can find: The tensile force of the outermost layer of aluminum lines, burned by wildfires and firewood, decreases obviously, and the elongation of these lines increases substantially. The tensile force of the outermost layer of aluminum lines burned by wildfires decreases by $64.7 \%$, the elongation of these lines increases to $21.97 \%$ from $2.16 \%$; The tensile force of the outermost layer of HVT lines burned by firewood decreases by $62.2 \%, 62.0 \%, 61.8 \%$, and the elongation of these lines increases to $27 \%, 32 \%, 34 \%$.

The tensile curve of the outermost layer of aluminum lines under different burning circumstances, are shown in Figure 9. The tensile force of the outermost layer of aluminum lines of the four HVT lines is similar basically, while the tensile force of the first HVT lines burned by firewood is most close to the result of wildfires. For elongation, the elongation of HVT lines burned by wildfires is smaller, while the elongation of HVT lines burned by firewood increases with the the increase of the degree of burning.

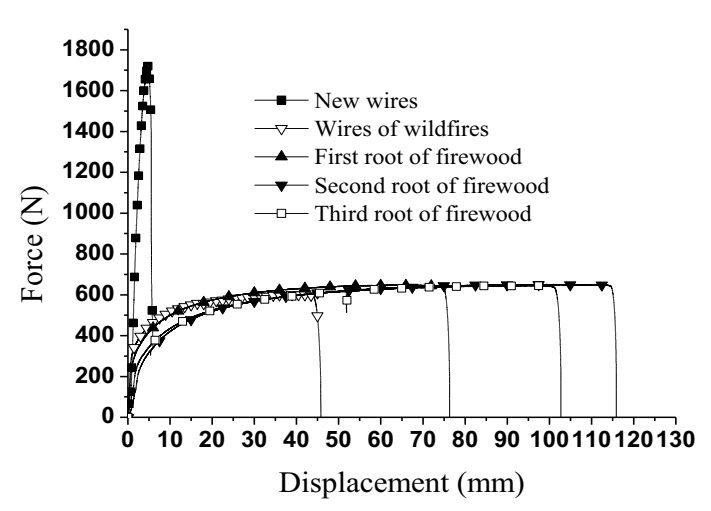

Figure 9. The tensile curve of the outermost layer of aluminum lines under different burning circumstances

4.3.3 The change of mechanical properties of steel core

From the above table(Table1,2,3 )we can find: The steel core's tensile force burned by wildfires is slightly larger than new HVT lines; the tensile force of the first steel core burned by firewood is slightly smaller than new HVT lines, the tensile force of second steel core decreases by $19.6 \%$, and the tensile force of third steel core decreases by $24.8 \%$. The elongation of all steel cores is very small in the whole process of experiment.

\subsubsection{The overall analysis of the mechanical properties of HVT lines after fire}

The change of the mechanical properties of HVT lines under different burning circumstances is shown in Table 4 .

From the Table 4 we can find: No matter what burning circumstances, the tensile force of single lines after fire has a corresponding decrease(except the steel core burned by wildfires), and the elongation of these lines has a corresponding reduction increase. For the outermost layer of aluminum lines, the change of the tensile force under different burning circumstances is almost same. For the second and third layers of aluminum lines, the change of the tensile force under firewood is much higher than the change of the tensile force under wildfires. For steel core, the change of the tensile force under firewood exist bigger fluctuation, but the tensile force under firewood is smaller than the tensile force under wildfires. Experimental results show that, the outermost layer of all HVT lines appear loose strands. This phenomenon shows, the outermost layer of HVT lines won't absorb load or will absorb little 
load. Table 4 shows that, if the outermost layer of HVT lines is ignored, the overall tensile force decreases with the increase of the degree of fire. Therefor, the overall tensile force of HVT lines can be simulated by the maximal tensile force of steel core, and this simulation is on the safe side.

Table 4. The change of the mechanical properties of HVT lines

\begin{tabular}{|c|c|c|c|c|c|c|c|c|}
\multicolumn{7}{c|}{ under different burning circumstances } \\
\hline $\begin{array}{c}\text { The fire } \\
\text { environ- } \\
\text { ment }\end{array}$ & \begin{tabular}{r} 
The decrease of tensile force $\%$ \\
\cline { 2 - 9 } \\
layer
\end{tabular} & $\begin{array}{r}\text { Second } \\
\text { layer }\end{array}$ & $\begin{array}{r}\text { Third } \\
\text { layer }\end{array}$ & $\begin{array}{r}\text { Steel } \\
\text { core }\end{array}$ & $\begin{array}{r}\text { First } \\
\text { layer }\end{array}$ & $\begin{array}{r}\text { Second } \\
\text { layer }\end{array}$ & $\begin{array}{r}\text { Third } \\
\text { layer }\end{array}$ & $\begin{array}{c}\text { Steel } \\
\text { core }\end{array}$ \\
\hline New wire & 0 & 0 & 0 & 0 & 0 & 0 & 0 & - \\
\hline $\begin{array}{c}\text { Wire of } \\
\text { wildfire }\end{array}$ & 64.7 & 15.9 & 14.4 & -0.14 & 917 & 29.5 & 16.0 & - \\
\hline $\begin{array}{c}\text { First root } \\
\text { of } \\
\text { firewood }\end{array}$ & 62.2 & 59.7 & 56.2 & 0.856 & 1150 & 948 & 933 & - \\
\hline $\begin{array}{c}\text { Second } \\
\text { root of } \\
\text { firewood }\end{array}$ & 62.0 & 60.9 & 57.5 & 19.6 & 1381 & 1567 & 1496 & - \\
\hline $\begin{array}{c}\text { Third } \\
\text { root of } \\
\text { firewood }\end{array}$ & 61.8 & 62.0 & 59.2 & 24.8 & 1474 & 1662 & 1496 & - \\
\hline
\end{tabular}

\section{Conclusions}

1 After wildfires, the tensile force of aluminum line decreases obviously, and plastic deformation of aluminum lines increases obviously.

2 After wildfires, the tensile force of steel core decreases not obviously than aluminum lines. The decreased degree is related with the burning degree, but plastic deformation does not change basically.

3 After wildfires, aluminum lines are fluffy and plastic deformation increases obviously. According to this phenomenon, steel cores provide the main load capacity.

4 With the burning degree rising, the tensile force of aluminum lines fell sharply at first and become stable at last. The tensile force of steel core reduces gradually and the tensile force of the whole HVT lines reduces gradually.
5 There is some difference between experimental simulation of wildfire and actual wildfire. But from the simulation results, mechanical properties of conductor burned by simulated wildfires can still accurately reflect that of conductor burned by wildfire. It can make guidance for deeper research in the future.

\section{References}

1. ZHANG Yun,YOU Fei,CHEN Hai-xian,ZHANG Lin-he,ZHU Ji - pin,ZHOU Jian-jun.Statistical analysis of wildfire accidents inducing flashover of transmission lines $[\mathrm{J}]$.Fire Sdenee and Technology(2011),In Chinese

2. MA Xiao-ming, FAN Chun-ju, HU Tian-qiang, HU Yi-zhong. Calculation of current carrying capacity of overhead transmission line based on thermal stability constraint $[\mathrm{J}]$.Power System Protection and Control(2012),In Chinese

3. GUO Hao - kun,HENG $\mathrm{Si}-\mathrm{kun}, \mathrm{YING}$ Zhanfen,WO Jun-ji.Research on On-line Monitoring System for Overhead Transmission Line Conductors Galloping $[\mathrm{J}]$.Science Technology and Engineering(2012),In Chinese

4. ZHANG Lizhong.Design of conducting wire temperature online inspection system for high - voltage transmission line[J].Heilongjiang Electric Power(2011), In Chinese

5. DI NG Fa-oing YU Zhi- wu WEN ai-lin.Experimental Research On Mechanical Properties Of 0235 Steel after High Temperature Treatment[J].]OURNAL OF BUI LDI N MATERI ALS(2006),In Chinese

6. Qin Li,LI JunKuo,Fu Qiang.Research on Aluminum Conductor Steel-reinforced Mechanical Characteristics of Transmission Lines[J].Water Resource of Power(2013), In Chinese

7. Zheng Liyang,Sun Zuzhi.Stress Analysis of Aluminium Stranded Wire and Steel-cored Aluminium Stranded Wire[J].Wuhan Univ of Hy dr .\&Elec.Eng(1997),In Chinese 